\title{
The Development of Cross-cultural Education in College English Translation Teaching
}

\author{
Shuling Song \\ School of International Education, Shandong Xiehe University, Jinan, 250100, China
}

Keywords: Cross-cultural education, College English, English translation.

\begin{abstract}
Translation activities are faced with both linguistic and cultural barriers. Translation is a cross-cultural and cross-linguistic communication activity. This paper analyzes the common features of translation education and cross-cultural education, and highlights the key points of the development of cross-cultural education in college English translation teaching, including reforming teaching model of translation education, cultivating cross-cultural awareness in translation education and cultivating cross-cultural ability in translation education to provide some references for the relative researchers.
\end{abstract}

\section{Introduction}

Translation activities are faced with both linguistic and cultural barriers. On the one hand, Chinese and English belong to two different language families. Chinese belongs to the Sino-Tibetan family of languages, and English belongs to the Indo-European language family. In the long process of evolution and development, the inherent rules and characteristics of Chinese and English have formed their own national characteristics in pronunciation rules, word structure, sentence structure and rhetoric aspects between the two, although there is no lack of common or similar, but there are obvious differences. On the other hand, language is the enrichment of all the cultural information of a nation. Language is not only an organic part of culture, but also an important carrier of culture. Each language is the product of the development of a nation and a nation. It has its historical origins and rich cultural connotations. The accurate grasp of semantics and the flexible use of expressions require a fuller and profound understanding of the culture represented by the language. All aspects of language translation are influenced by cultural differences. Intercultural awareness refers to the understanding of the similarities and differences between the two cultural patterns that influence the thinking and behavior of the mother tongue culture and the foreign culture. Translation is a cross-cultural and cross language communication and communication activity. Language is a carrier of culture. At the same time, culture is also the soil on which language depends. The language teaching but also cultural education, only let students learn more about English culture, contrastive analysis of English and Chinese culture much more attention to the above similarities and differences, pragmatic features and intercultural communication requirements, in order to truly improve students' intercultural communicative competence in intercultural communication, will make the activities carried out smoothly. With the concept of diversification, diversification of learning English knowledge is gradually recognized, intercultural communication study in China both in theory, content and method will be referred to a higher level. At the same time, we should also be more clear understanding of the level of intercultural communication teaching, the current situation of our country. The students and teachers should be synchronized with a more rational approach to learning to study, learning and innovation with more effective measures and methods. The spread of cross culture and cross language determines the particularity of communication channels, it is a kind of communication using a specific language, information conversion, encoding is the use of specific language between two cultures. In today's era of economic globalization and cultural diversity, language translation plays an indispensable role in communication and communication, enriching 
human culture and promoting the integration of all ethnic groups. Translation competence is essentially a cross-cultural communicative competence.

\section{Common Features of Translation Education and Cross-cultural Education}

Common Feature of Language. Communication cannot be separated from the media and symbols. Media load symbols, symbols, load information. Symbols and media are the intermediary for all communication activities. The core of communication is information, and it is the flow of information. In human communication, there is neither the dissemination of information nor the dissemination of information. Culture exists in the form of symbols, and the purpose of culture is to spread. Any symbol can be acquired in meaning and value only when it is transmitted. Without communication, symbols have no meaning, and culture loses the possibility of existence. Therefore, intercultural communication cannot be separated from the original symbols of language and human beings. It is through these languages and symbols that information can be exchanged, communication of values and reconstruction of meaning can be realized. Translation, as the main mode of intercultural communication, needs more and more reliance on language and symbols than other factors. Cultural background is broad in meaning and coverage. Not only refers to the difference between different cultures and regions, but also refers to the differences between the same cultural region and different cultural regions. From the essence of cross-cultural communication, the differences in cultural backgrounds lead to misunderstandings in the process of communication, and communication cannot be carried out smoothly. The premise of communication is that the language of both sides is unified. If the communication between the two sides of the communication is blocked, the communication cannot be carried out. In the actual process of communication, the language is native language for one party to the other party, it is then used to the actual exchange of the native language is on the one hand, and on the other side is the second language.

Common Feature of Target. Cross culture education is a conscious and purposeful activity of human beings. The main body of communication hopes to achieve a certain purpose and effect. It can be said that intercultural communication is a social activity that transmits information, ideas and feelings dynamically between heterogeneous cultures, as well as human communication and communication related to it. Similarly, human translation is always in control of a certain sense of purpose and direction of cognitive activity of a subject, that is to say, no intention of cross cultural dissemination and translation is not exist. In cross-cultural communication, communicators collection, selection, processing and processing of information in almost every link in conscious cross-cultural creation, embodies a certain intention and purpose. Language is an important part of culture. It is derived from the historical accumulation and life experience of the nation. If we do not understand the cultural background of the language we learn, we cannot understand and use the language we are learning. Therefore, we should train students to master the language knowledge and skills for the purpose of language teaching. In essence is a kind of cross-cultural communication, we should not only teach students vocabulary and grammar, and let the students master the basic knowledge of language and culture, but also let the learning through the language of the national culture and more in-depth understanding of the cultural differences, so that more effective and comfortable to use cross-cultural communicative language teaching. Translation is essentially a cross-cultural communication. We should not only teach students vocabulary and grammar, and let the students master the basic knowledge of language and culture, but also let the learning through the language of the national culture and more in-depth understanding of the cultural differences, so that more effective and comfortable to use cross-cultural communicative language teaching.

Common Feature of Interaction. Translation activities and cross-cultural communication are both two-way, which is the process of information sharing and two-way communication between translators and readers. Among the common interpersonal communication and communication, there are two kinds of one-way communication, namely, one-way communication without feedback and two-way communication with feedback. The linear propagation model distinguishes the fixed position and function of communicators and receivers, but ignores the role of communicators and receivers. In two-way communication, the communicator and receiver play the same role. The two 
parties are interactive and use the same encoding, decoding and decoding functions. Because culture is dynamic, always in constant communication, and culture is diverse, heterogeneous, so it is not closed, one-way communication, two-way, interactive, but even this is multidimensional, intercultural communication and intercultural communication as the common translation feature. Translation is a language conversion but not from the source language to the target language requirements on the mechanical text translation, it requires the translator as far as possible to understand the original author's ideas on the basis of the content of the original complete and accurate expression, which requires not only the translator has a sufficient knowledge of English must have enough, but also requires the translator the knowledge of English culture, otherwise cannot translate the original thoughts, deviated from the central meaning of the author, it is not good to grasp the gist of the article. The study and mastery of intercultural communication knowledge is an important way to improve students' English translation ability.

\section{Key Points of Cross-cultural Education in College English Translation Teaching}

Reform Teaching Model of Translation Education. The traditional classroom teaching model takes unit teaching as its theme, emphasizes the accuracy of intonation, pronunciation and grammar, and focuses on the collocation and use of vocabulary. Obviously, this is because the teacher has not yet got rid of the influence of the exam oriented education, and will focus on training the students' ability to take exams, but ignore the most critical cultural factors. For the time being, the most common teaching mode is for teachers on the platform. Students listen to the platform, and after class they do endless homework and exercises. Although the students who have such a strong foundation have the ability to do regular English writing, they cannot become excellent translators. The root of the problem lies in the great differences between Chinese and Western cultures. Therefore, teachers must reform the current teaching model, pay attention to the infiltration of cultural knowledge in the classroom teaching, and cultivate students' cultural awareness. The contemporary popular college English textbook is no longer an independent individual with knowledge, but is endowed with many cultural factors. From the teaching materials, students can understand and cultivate foreign culture, politics and economy. English teachers should make full use of extracurricular activities to create opportunities for students to understand English culture and develop communication skills. As for some English speech contest, English debate, organize students on a cultural phenomenon and cultural contents of English speech, debate, drama activities can be held, textbook drama based on encouraging students to imagine a bold, bold and innovative. Teachers can also hold English corners, English salons, special lectures and foreign language films or music appreciation meetings. Let students know more about the learning, living and working conditions in the English-speaking countries. Thus, we can really experience western culture and enter into cross-cultural appreciation and communication.

Cultivate Cross-cultural Awareness in Translation Education. The influence of culture on people is so great that it often puts its first impressions on foreign cultures and explains its unfamiliar culture with its own cultural significance. In the long-term impact of China's traditional teaching mode and examination oriented education, many teachers lack of cross-cultural awareness education, only pay attention to language knowledge in teaching, while ignoring the students' communicative ability of this teaching model has been unable to meet the development of college English teachers should constantly improve their comprehensive quality, have full understanding of their traditional culture, and under the conditions allowed to visit abroad, the exotic culture in foreign exchange and visit the school experience back to classroom, to help students with objective, equal awareness of cross-cultural communication, to understand the similarities and differences between native culture and target culture, establish the correct cross-cultural communication view. Only in this way can cross-cultural education be integrated into foreign language teaching and eventually the goal of intercultural education will be achieved. The role of teachers in teaching is beyond doubt. As a cross-cultural understanding of education and promoters, teachers themselves should have strong cross-cultural awareness, so as to cultivate cross-cultural awareness of students which requires teachers to improve their own culture through a variety of methods, familiar with the teaching 
materials especially in English speaking countries cultural background knowledge, take the initiative to understand the differences between the western culture with equality in, to establish the correct cultural values, so that they have the ability to understand both cultures. In addition, teachers as intercultural education should pay attention to their own character, usually receive continuing education training, so that they have a solid professional basis, broaden the knowledge of cross cultural education in teaching, improve the intercultural education consciousness.

Cultivate Cross-cultural Ability in Translation Education. In cross-cultural communication, cultural empathy is the bridge and link between language, culture and emotion that connects the subject and the object, as well as the skills, art and ability to communicate effectively. The ability of cultural empathy is closely related to the cultivation of intercultural communicative awareness. Therefore, teachers should guide students to pay attention to the differences between Chinese and Western cultures in the course of teaching, so that students can consciously avoid translating errors caused by cultural differences between China and the west. For example, Chinese praise for others usually responds modestly with modesty. And the west is different, they will gladly accept other people's praise and express gratitude. Because of the interaction and infiltration between the two cultures of China and the west, a large number of Chinese have entered English and become part of standard English. In recent years, with the rapid increase of China's reform and opening up, foreign propaganda and communication, China unique things of English vocabulary in the field of expression of the emergence of a large number of political and economic, social and cultural, daily life, at the lexical, syntactic and textual aspects of English influence cannot be ignored, China is in English the formation of a unique international communication tool. In humans in twenty-first Century, with the progress of science and technology, the development of the society and the wide dissemination of information, exchange and cooperation of international economy, politics, education and science and technology increasingly, between the state and the nation's increasingly frequent exchanges and contacts, promote mutual penetration and exchanges between different cultures, accelerated the blending of different cultures and convergence. Language is a cultural carrier and a communication tool, cultural convergence will be directly reflected in the trend of the integration of language, at the same time, the fusion of the language changes will also reflect and record the evolution of cultural convergence. As a bridge of cross-cultural communication, language translation plays an indispensable role in communication, cultural communication, enriching human culture and promoting cultural convergence.

\section{Conclusion}

Nowadays, international communication is becoming more and more frequent. Teachers should introduce the cross-cultural communication and education into the college translation teaching. College teachers should reform the teaching model and attach great importance to cultivating students' intercultural awareness and intercultural competence to make translation become purposeful cross-cultural communication activities. While mastering the translation skills, students are able to understand cultural differences, prompting them to become truly competent translators.

\section{References}

[1] Su Guangcai, Li Shuangjuan. Nurturing Students Sense of Cross- cultural Communicationthrough a Translation Course of College English [J]. Shanghai Journal of Translators, 2014(4): 52-54.

[2] Liu Yunfei. The Best Means for the Cultivation of Cross-culturalCommunicative CompetenceThe Status and Role of Translation in English Education [J].Journal of Jiangsu Normal University (Philosophy and Social Sciences Edition), 2013, 4(4): 53-57.

[3] Chen Xian. On the Application of Multimodal Metaphor in Cross-culturalEducation in College English Teaching [J].Journal of Taizhou University, 2015, 37(5): 68-71.

[4] Chen Wenhua. On Cross-Cultural Education in College English Teaching [J]. Journal of Changchun Normal University (Humanities and Social Science), 2014, 33(4): 169-172. 